\title{
Josef K. y la culpa. Una reflexión a propósito de la teoría del sujeto de Althusser.
}

\section{Josef K. and the guilt. A reflection on the subject theory of Althusser.}

\author{
Roberto Israel Rodríguez Soriano \\ Instituto de Educación Media Superior de la Ciudad de México Universidad Autónoma del Estado \\ de Morelos (MÉXICO) \\ CE: roberto.i.soriano@gmail.com ID ORCID: 0000-0002-7088-103X
}

DOI: $\underline{10.32870 / \text { sincronia.axxiii.n76.5b19 }}$

(C) $\mathrm{BY} \cdot \mathrm{NC}$

Esta obra está bajo una Licencia Creative Commons Atribución-NoComercial 4.0 Internacional

Recibido: 30/01/2019

Revisado: 04/03/2019

Aprobado: 28/03/2019

\section{RESUMEN}

En este trabajo se ofrece una interpretación del concepto de la culpa, tomando como elemento de análisis la obra de Franz Kafka El proceso. Dicha interpretación es guiada teóricamente por el concepto de sujeto desarrollado por Louis Althusser que abreva de la teoría psicoanalítica freudiana y lacaniana.

La culpa es un mecanismo psíquico que exige la restitución de un orden quebrantado. Al ser subjetiva, la realidad fáctica del quebrantamiento del orden pasa a un segundo término. La realidad esencial de la transgresión es psíquica, interna y personal. Por tal motivo el sentimiento de restitución del orden quebrantado puede tener o no que ver con un quebrantamiento factico de una norma, pero que su realidad no depende de esto último.

La culpa proviene del incumplimiento de la ordenanza del Otro, que es el gran Sujeto que remite a la constitución primaria de la psique humana en la forma del Superyó. 
Palabras clave: Culpa. Sujeto. Interpelación. Kafka. Althusser. Freud. Lacan.

\begin{abstract}
:
In this work was made an interpretation of the concept of The Fault, taking as an element of analysis the work of Franz Kafka The process. This interpretation is guided theoretically by the concept of the subject developed by Louis Althusser, which draws it on the Freudian and Lacanian psychoanalytic theory.

The fault is the psychic mechanism that demands the restitution of a broken order. Being subjective, the factual reality of the breach of order passes to a second therm. The essential reality of transgression is psychic, internal and personal. For this reason, the feeling of restitution of the broken order may or may not have to do with the factual breach or a norm, but that its reality does not depend on the last.

The Fault comes from the non-compliance of the Other's ordinance which is the great subject that refers to the primary constitution of the human psyche in the form of the superego.
\end{abstract}

Keywords: Fault. Subject. Interpellation. Kafka. Althusser. Freud. Lacan.

"A veces creo expiar todas las culpas pasadas y futuras a través de los dolores de mis huesos..." Franz Kafka (2007, p. 46)

\title{
Introducción: Josef K. y el proceso
}

Josef $K$. fue sorprendido una mañana por un par de agentes vestidos de traje negro que le informaron que estaba arrestado. K. preguntó por qué. Uno de los agentes le respondió: “No nos han encargado decírselo. Métase en su habitación y espere. Acaba de iniciarse la instrucción del proceso, y se le informará de todo a su debido tiempo" (Kafka, 2001, p. 13).

K. preguntó varias veces el motivo del arresto. Le dijeron que quienes los mandaban no trataban de localizar la culpabilidad entre la población sino que, como dice la ley, la misma población se sentía llamada por la culpabilidad y entonces los enviaban a ellos, los guardianes. K. los 
interpeló preguntándoles que cuál es esa ley que él no la conocía. A lo que los guardianes le respondieron: "Tanto peor para usted" (Kafka, 2001, p. 12).

Después de un rato le informaron que el inspector había llegado. K. fue conducido a la habitación de la señorita Bürstein, su vecina. Inició un diálogo con éste. En una parte del diálogo K. dijo, exigiendo algún tipo de explicación sobre la situación:

[...] soy acusado, pero no puedo hallar ni la más mínima culpa por la que se me puede acusar. Aunque también esto es accesorio; la cuestión principal es saber de quién viene la acusación. ¿Qué autoridad instruye el procedimiento? ¿Son ustedes funcionarios? (Kafka, 2001, p. 13).

El inspector le respondió:

'Está usted en un grave error', dijo. 'Estos señores y yo desempeñamos un papel muy subalterno en el asunto de usted, e incluso podemos decir que no sabemos casi nada de él. (...) Tampoco puedo decirle que sea usted acusado, o mejor, no sé si lo es. Usted está arrestado, es cierto, y no sé nada más. (...) Y no arme tanto alboroto con el convencimiento de su inocencia, porque empeora la impresión, no del todo mala, que usted causa' (Kafka, 2001, p. 17).

Después de seguir dialogando con el inspector, sin respuesta específica, le permitieron ir a su trabajo. Así inicia el relato del muy accidentado, incomprensible, rebuscado, absurdo, oscuros, obtuso e inútil camino que recorrerá K. para poder comprender algo de la circunstancia del proceso judicial en el que está inmerso.

El relato termina con la muerte de K. (que no representa el fin del proceso). Los agentes van por K. a su casa. Lo escoltaron flanqueado por cada lado hacia la calle. Da la impresión, por sus reflexiones, que K. sabe que será asesinado. Llegaron a un punto de la calle que estaba en pendiente y los agentes acostaron a K. en el suelo. Uno de los agentes le desabrochó la levita y sacó un cuchillo. Los agentes jugaban con el cuchillo. Se lo pasaban uno al otro. Para este momento K. tenía certeza de que lo iban a asesinar y que esa era su sentencia. En ese momento se preguntaba 
“¿Dónde estaba el juez que no había visto nunca? ¿Dónde estaba el alto tribunal al que nunca había llegado?". Después levantó las manos mientras uno de los agentes le agarraba la garganta y el otro le enterraba el cuchillo en el corazón: “Con los ojos vidriosos, K. vio aún cómo los señores, muy cerca de su cara, mejilla contra mejilla, observaban la decisión. «iComo un perro!», dijo; era como si la vergüenza hubiese de sobrevivirle" (Kafka, 2001, pp. 228-234).

El Proceso inicia mostrando que el inicio no es el inicio. Muestra que aún antes del inicio hay algo. Cuando comienza la narración Josef K. ya está desde hace tiempo inmerso en un proceso legal del que él se está recién enterando. K. no comprende de qué se le acusa, sin embargo, conforme va desarrollándose la narración va asumiendo con una asombrosa naturalidad su papel dentro del proceso, hasta morir convencido de su culpabilidad. La ley lo interpela y él asume la interpelación de la misma manera que todos los demás personajes con los que se relaciona. Lo hace a tal grado que K. se deja asesinar sin oponer la mayor resistencia. Muere siendo culpable, sin saber exactamente de qué. Tal vez una culpabilidad que nada o todo tiene que ver con el proceso.

Franz Kafka muestra desde las entrañas de esa fantasmagoría tan real, llamada Estadonación, que el individuo moderno no puede liberarse por ningún medio de su sujeción. Una de las lecciones que aprende $K$. es que preguntarse y tratar de responderse por los motivos de esa sujeción es una forma de atraparse más y acelerar el proceso inevitable. Es inútil la pregunta porque no hay respuesta; no hay justificación, no hay fundamento, solo hay la "nada". La fuerza burocrática estatal no sabe de fundamentos, no los necesita. La ficción creada por la modernidad y sus procesos democráticos (el pacto social, el bien común, la ciudadanía y la representación) esconden el vació de fundamento. Kafka lo sabe. A partir del ejercicio literario y sus posibilidades plásticas, desnuda esta gran ficción. Con una prosa cruda muestra una realidad cruda. Muestra que las posibilidades de liberación no están donde se creen. La mitología se perpetúa a través de sus formas institucionales y sistémicas. Es inútil pedir justicia; justificación legal a quien no necesita otorgarla.

Nos encontramos junto a Josef $\mathrm{K}$. recorriendo esos barbáricos laberintos que configuran la política institucional. Parecería que K. es un ser desahuciado, no obstante que a momentos recupera su dignidad, para perderla una y otra vez. Paradójicamente, la recupera sólo cuando 
asume su papel dentro del círculo que lo acusa y que lo condenará a muerte. Es una paradoja insuperable. Buscar una racionalidad es fútil, de manera que el absurdo es lo cotidiano, es la normalidad en que estamos acostumbrados a vivir.

Entonces, ¿cómo puede ser explicada esa sujeción? ¿cómo puede ser teorizada la constitución de esa subjetividad a partir de la cual K. y todos nosotros, somos enrolados en los diferentes procesos que nos lleva a asumir esa subjetividad y a escuchar la interpelación? La hipótesis de inicio tiene que ver con la interiorización de la culpa.

\section{La constitución del sujeto en la teoría althusseriana de la interpelación ideológica}

Althusser propuso que la ideología, por un lado, "representa la relación imaginaria entre los individuos y sus condiciones reales de existencia" (Althusser, 1977, p. 112). Por otro, que ésta "tiene una existencia material" (Althusser, 1997, p. 116).

La primera de estas dos tesis apunta a que la ideología forma una concepción del mundo imaginaria, la cual, al ser imaginaria, no corresponde a la realidad. La ideología se presenta, así, como una ilusión. En la ideología, en palabras de Althusser: “los hombres se representan a sí mismo bajo una forma imaginaria sus condiciones de existencia reales" (1997, p. 113). Con esta tesis Althusser quiere explicar el comportamiento de del sujeto que actúa como si fuera la fuente coherente de significados y, por otra parte, llama la atención hacia la subjetividad para que pueda pensarse teóricamente el valor de la ideología, y no el que la ilusión sea engendrada por las mentiras de las clases sociales dominantes (Aguilar, 1984, 61).

Dice que la deformación que implica la ideología representa, no las relaciones de producción, sino la relación de los individuos con las relaciones de producción y las que se producen de éstas. La ideología estaría representando la relación imaginaria de los humanos con las relaciones reales en que viven. Planteado el problema de esta forma, la pregunta sobre la "causa" de la deformación imaginaria de las relaciones reales, se transforma en un falso problema. La pregunta se debería reformula a: “¿por qué la representación que adquieren los individuos de su relación (individual) con las relaciones sociales que rigen sus condiciones de existencia y su vida 
colectiva e individual es necesariamente imaginaria?” (Althusser, 1977, p. 115) o bien “¿Cuál es la naturaleza de esta representación imaginaria?" (Althusser, 1977, p. 115).

Parece que la formulación de Althusser tiene el sentido de que la ideología representa la forma en que los humanos podemos conceptuar la manera en que nos relacionamos con el mundo y entre nosotros mismos.

La segunda tesis de Althusser sobre la ideología: ésta tiene una existencia material. Primero, esta tesis se apoya en el supuesto de que las "ideas" tiene una existencia material. Esta suposición sirve a Althusser para contextualizar el concepto de ideología, en el sentido en que afirma que "una ideología existe siempre en el seno de un aparato, y en su práctica o sus prácticas" (1977, p. 116). En este último sentido, afirma que la existencia de ésta es material. En otras palabras, es material porque se sustenta, aunque sea de forma imaginaria, en prácticas materiales.

En este punto lo que le interesa a Althusser plantear es la situación de los "individuos" que viven dentro de la ideología, es decir, en una determinada representación del mundo, la cual es deformada a través de su relación imaginaria con las condiciones de existencia. En otras palabras, las relaciones sociales de producción. El individuo que participa en una ideología tiene un conjunto de creencias manifestadas en ideas que el individuo alberga en su conciencia. El que el individuo tenga una conciencia, argumenta Althusser, implica que reconoce libremente ciertas ideas en las que cree (1977, p. 117). De esta manera, el individuo participa de prácticas reglamentadas a partir de las cuales determina su comportamiento práctico. Estas prácticas reglamentadas son las que conforman el aparato ideológico. Sin embargo, debe señalarse que el individuo escoge libremente, es decir, con plena conciencia, las ideas que configuran su actuar. Pero las ideas que puede escoger el individuo están enmarcadas en una ideología.

Para Althusser el que el individuo tenga conciencia y que crea en las ideas que la misma conciencia le infunde ( $y$ acepta libremente), implica que éste, el individuo, debe de actuar de acuerdo con estas ideas:

Así pues, este esquema muestra que la representación ideológica de las ideologías se ve obligada a reconocer que todo sujeto dotado de una "conciencia", que cree en las "ideas" que ésta 
le inspira y las acepta libremente, debe de actuar de acuerdo con sus "ideas"; debe, por lo tanto, inscribir sus propias ideas de sujeto libre en los actos de su práctica material. Si no lo hace, "no actúa correctamente".

La premisa central de la idea anterior es el que los sujetos que están dotados de una conciencia deben de creer en las ideas enmarcadas por una ideología. Deben, éstos, actuar de acuerdo con estas ideas. Estos actos, según Althusser, se encuentran insertos en prácticas. Éstas, a su vez, se encuentran reglamentadas por rituales en los cuales se inscriben. En otras palabras, "dentro de la existencia material de un aparato ideológico" (1977 p. 118). De esta manera, el sujeto actúa impulsado por el marco ideológico.

Ese marco ideológico es dentro del cual los sujetos se constituyen como tales como sujetos. La ideología tiene como función "constituir" a los individuos concretos en sujetos. Hay que añadir algo más. El individuo desde siempre vive en la ideología, por ende, es desde siempre ya sujeto. Althusser señala, dentro de esta afirmación, que la función de la ideología es imponer "evidencias" como evidencias que no se pueden dejar de "reconocer". Podemos decir que las "evidencias" a que hace referencia, en última instancia, es el lenguaje, en tanto que es un constructor social y que penetra todas las actividades humanas. Por este motivo la afirmación de que los individuos son desde siempre sujetos.

Es importante señalar la acción del reconocimiento ideológico. La ideología como constituyente de sujetos implica la idea de reconocimiento.

Así, el reconocimiento ideológico es inmediato para el sujeto que capta y reconoce el mundo a partir de la ideología. Entonces, ser sujeto significa reconocer las interpelaciones de la ideología dirigidas a sí mismo, y que por esta acción, éste se reconoce como sujeto.

La ideología interpela a los individuos en tanto sujetos. Inclusive, los individuos son sujetos aún desde antes de su nacimiento. En este sentido el la ideología al interpelar sujeta y predestina al individuo, haciéndolo sujeto.

Con base en estas tesis, Althusser se propone analizar cómo se da la interpelación dentro de la ideología religiosa cristiana. Para comenzar este examen propone el siguiente postulado: la 
estructura formal de toda ideología es siempre la misma. Esta idea se articula con la tesis: "la ideología en general no tiene historia". Este último enunciado se refiere a que, con fines analíticos, se puede decir que la ideología tiene una estructura y un funcionamiento ahistórico. Es decir, su estructura y funcionamiento en cualquier momento de la historia es el mismo.

Después de hacer una reflexión amplia sobre la religión y la interpelación, asumiendo la idea de que en ésta Dios es quien interpela a los sujeto dándoles nombre propio, dándoles una identidad personal, a lo cual el individuo responde "sí, ciertamente soy yo!". Es decir, la interpelación les da, a los individuos, un lugar y una identidad determinados:

Si obtiene en la interpelación [Dios] la garantía de que los sujetos ocupan efectivamente el lugar que se les designa como suyo propio en el mundo, un puesto fijo: “ien verdad, yo soy aquí (...) obrero, patrón, soldado!"; si obtiene de ellos el reconocimiento de un destino (...) según respeten o desprecien los "mandamientos de Dios", (...) si ocurre todo esto (en la práctica de lo bien conocidos rituales de bautismo, la confirmación, la comunión, la confesión, la extremaunción, etc.), no podemos por menos que señalar que este "modo de hace", donde vetan en escena sujetos religiosos cristianos, se halla dominado por un extraño fenómeno, a saber: la imposibilidad de que exista tal multitud de posibles sujetos religiosos a no ser bajo la condición absoluta de que hay Otro Sujeto Único, Absoluto: Dios (Althusser, 1977, p. 129).

Entonces, la interpelación que supone esta ideología presume un sujeto; un Sujeto otro, único y central, en cuyo nombre la ideología, en este caso, religiosa, interpela a los individuos en tanto que sujetos. Se puede pensar que ésta es la estructura y funcionamiento de cualquier caso de ideología. En nombre de un Sujeto Único y Absoluto (con mayúsculas) la ideología interpela a los sujetos en tanto tales. Althusser señala que este Sujeto Absoluto ocupa un lugar central, ya que a partir de allí se interpela a la infinidad de sujetos que existen a su alrededor. De esta forma, la ideología, somete a los sujetos al Sujeto, y, asimismo, les ofrece la garantía de que todo ocurre entre ellos y Él.

Ese Sujeto, no sólo se refiere a Dios. Ese Sujeto es en nombre de quien interpela la ideología al sujeto. Pero, ¿qué o quién es ese Sujeto? Este Sujeto podría referirse a una instancia que 
trasciende al sujeto, y que, sin embargo, determina su conformación como tal. Esta determinación penetra en lo más íntimo del sujeto: en la estructura de su constitución psíquica. Pero ¿qué significa esto?

\section{Freud y Lacan: la conformación del ideal del yo}

Sigmund Freud en su trabajo de 1923, El yo y el ello, establecía la caracterización del yo y del ello, definiendo al primero como la parte racional de la psique y al segundo como la parte pasional (Freud, 2001, p. 27). El yo depende de la conciencia. Éste gobierna los accesos a la motilidad. Es decir, gobierna los accesos a la descarga de las excitaciones en el mundo exterior, y es la instancia anímica que ejerce control sobre los procesos de percepción. El yo juega un papel determinante en los procesos de represión. El yo controla y discrimina las "aspiraciones anímicas" que deben excluirse de la conciencia. Sus "estratos" de dominio son el preconsciente y el consciente. Éste confluye con el ello a través de los procesos de represión. Éste último es el representante de las pulsiones que son esencialmente inconscientes.

Sin embargo, el yo sufre el influjo de otra instancia anímica que se conforma a lo largo de la maduración psíquica del individuo, específicamente en la fase sexual gobernada por el complejo de Edipo: el ideal del yo.

Siguiendo a Freud, en la fase primitiva oral del individuo es imposible, para éste, distinguir entre investidura de objeto e identificación. Las investiduras de objeto parten del ello, el cual siente las aspiraciones eróticas como necesidades. Entonces, el yo, endeble en ese momento recibe noticia de la investidura de objeto. Le da su consentimiento, pero a través de una censura mediante el proceso de represión. El objeto sexual es dotado de una nueva investidura. Freud señalaba que este proceso es frecuente en las fases tempranas en el desarrollo de la pique humana. Entonces, el carácter del yo sería una "sedimentación de las investiduras de objeto resignadas, contiene la historia de estas elecciones" (Freud, 2001, p. 31).

El yo, al cobrar los rasgos del objeto, se impone al ello como objeto de amor buscándole reparar su pérdida cumpliéndose así, la trasposición de libido de objeto en libido narcisista. 
En el caso concreto del niño varón, Freud expone el siguiente proceso: 1) el niño desarrolla una investidura de objeto hacia la madre; 2) el niño se apodera del padre a través de identificación; 3) ambos vínculos van de la mano, hasta que, por el refuerzo de los deseos sexuales hacia la madre, y por la percepción de que el padre es un obstáculo para estos deseos nace el complejo de Edipo; 4) la identificación-padre adquiere un carácter hostil, nace el deseo de aniquilar al padre para sustituirlo; 5) a partir de este momento su relación con el padre es ambivalente; 6) posteriormente, con la superación del complejo de Edipo la investidura de objeto de la madre debe de ser reasignada. Lo cual puede tener dos posibles diferentes tipos de reemplazos: una identificación con la madre o un refuerzo de la identificación-padre. Freud estableció el resultado de la fase sexual gobernada por el complejo de Edipo de la siguiente manera:

Así como resultado más universal de la fase sexual gobernada por el complejo de Edipo, se puede suponer una sedimentación en el yo, que consiste en el establecimiento de estas dos identificaciones, unificadas de alguna manera entre sí. Esta alteración del yo recibe su posición especial: se enfrenta al otro contenido del yo como ideal del yo o superyó" (2001, p. 35).

De esta forma se constituye el superyó o el yo-ideal. En tanto su carácter de ideal se impone tanto con la exigencia "Así debes ser", como "Así no te es licito ser". Posteriormente, el superyó mantendrá el carácter del padre, y entre más intenso fue el complejo de Edipo y más rápido se produjo su represión (por influencia de la autoridad, de la doctrina religiosa, de la enseñanza, la lectura), ejercerá su imperio, se convertirá en la conciencia moral

Freud señala que la sustitución de la añoranza del padre fue llevada a cabo por maestros y autoridades ya que sus mandatos y prohibiciones hacen vigente al ideal del yo, expresándose como la conciencia moral, es decir, como la censura moral.

Aquí podemos trazar el punto de encuentro con la propuesta althusseriana de la interpelación ideológica. La teoría de la interpelación de Althusser señalaba la existencia de un Sujeto a nombre de quien se interpelaba al sujeto. Este Sujeto tiene una resonancia enorme en la 
conformación de los individuos en sujetos ya que, como lo muestra Freud, penetra en lo más íntimo de la constitución psíquica. Me refiero a la conformación del ideal del yo. Este Sujeto debe ser caracterizado como la esencia de la autoridad (abstracta) que se impone al individuo en su identificación como Sujeto. Si deslizamos un poco la lectura de la propuesta althusseriana, este Sujeto, no se concibe solamente como la autoridad suprema estatal que interpela a los individuos, sino que puede ser anterior a ésta, y está presente desde las esferas más primarias de la actividad humana que conforman una sociedad. En este sentido el ideal del yo, en término freudianos, se conforma por la autoridad que impone al individuo la cultura. Sin embargo, se entrevé un problema. La constitución del yo está marcada por la serie de desplazamientos que se originan en el proceso de sustitución en la superación del complejo de Edipo, sin embargo, podría preguntarse cuáles son los contenidos de esos desplazamientos y sustituciones. En el sentido althusseriano podríamos plantear la idea de que el Sujeto, a través de la ideología, no interpela a todos los sujetos de la misma manera. El problema que creo que está de fondo es la dicotomía sociedad-individuo. A este problema se le puede dar un acercamiento más preciso a través de la reformulación psicoanalítica lacaniana.

Para Lacan la constitución del yo siempre acaece de una forma relacional. El niño, a la edad de 6 a 8 meses, se configura una imagen de sí mismo. Esta imagen está determinada por su relación con su madre que es la que funciona como punto referencial de identificación. En ese momento el niño adquiere una posición con respecto a otro objeto que es su propia imagen, lo cual le confiere unidad. Entonces, la unidad del "sujeto" se adquiere mediante la unidad de la imagen especular hacia la cual el niño proyecta su propia unidad. La imagen especular que construye el niño es el modelo para que éste pueda relacionarse con otros objetos. Esto le abre la entrada al mundo de lenguaje. Si la constitución identitaria del yo se construye a partir de imágenes especulares, es decir, mediada por el aspecto relacional, éste está constituido siempre por una ilusión (Stavrakakis, 2007, p. 43). Por lo que sólo le queda al niño volverse hacia el nivel simbólico que le confiere el lenguaje, un medio para poder adquirir una identidad estable: 
Sometiéndose a las leyes del lenguaje el niño se convierte en sujeto en el lenguaje, habita el lenguaje, y espera obtener una representación adecuada a través del mundo de las palabras: 'lo simbólico proporciona una forma en la cual el sujeto es insertado al nivel de sus existencia. Es sobre esta base que el sujeto se reconoce como siendo esto o aquello" (Stavrakakis, 2007, p. 43).

Así, el intercambio simbólico, el lenguaje, es lo que vincula entre sí a los seres humanos, en tanto que permite construir alguna identidad al sujeto (Lacan, 1985, p. 213). Este orden simbólico, paradójicamente, preexiste al sujeto.

El sujeto en su búsqueda de una identidad, la cual sólo puede llevarse a cabo en el orden de lo simbólico, a través de las leyes del lenguaje, se conforma como un "sujeto en falta". Esta falta es la imposibilidad de una completud identitaria que persigue el sujeto ya que ésta se encuentra por el Otro, en cuanto no es el mismo.

Como ya lo había mencionado, socialmente, según Lacan, nos definimos por el intermedio de la Ley. Ésta es el vínculo simbólico. Los sujetos sitúan sus diferentes "yos" a través del intercambio mutuo de símbolos (Lacan, 1985, p. 213). Esta relación simbólica define la posición del sujeto como vidente. Entonces, la palabra, la función simbólica, define el grado de aproximación de lo imaginario, es decir, la forma en que se constituye el yo por la intermediación del otro. En este sentido, el ideal del yo dirige el juego de relaciones de las que depende toda relación con el otro (Lacan, 1985, p. 214). El ideal del yo es otro en tanto hablante, en tanto tiene una relación simbólica el yo. El ideal del yo, en tanto hablante, puede llegar a situarse el mundo de los objetos a nivel del yo ideal, donde se puede producir la captación narcisista de la que hablaba Freud. Dentro de esta dinámica el sujeto se transforma en un efecto del significante. De esta forma, el "descentramiento radical de la subjetividad en Lacan, respecto al significante, se desprende de un particular entendimiento de este nivel simbólico, el registro del significante, el gran Otro" (Stavrakakis, 2007, p. 12). 
El sujeto, como se ha visto, es un esclavo del lenguaje. Con más precisión, el sujeto es avasallado por un discurso en "en el movimiento universal" en el cual, éste, está inscrito desde antes de su nacimiento, representado ya desde la imposición de un nombre propio (Lacan, 2005, 475). El sujeto nace inserto en la tradición que instaura ese discurso, es decir, se encuentra inserto en las estructuras "elementales de la cultura".

Lacan reformula la enunciación saussuriana en que se designaba al signo lingüístico como una entidad psíquica de dos caras en que al significante le correspondía un solo signo ( $\mathrm{S} / \mathrm{s}=$ significante sobre significado) (Saussure, 1945, pags. 127-130). Para Lacan el significante no funciona como una representación del significado. El sentido es producido por los significantes. El sentido es dado desde el significante hacia el significado. De esta manera el significante anticipa siempre el sentido que despliega éste mismo. Entonces, lo que crea el sentido en cada caso es el diferente significante. El significante manifiesta la presencia de una diferencia haciendo imposible la conexión ente los signos y las cosas. Es en la cadena del significante, mirada desde la perspectiva lacaniana, donde ninguno de los elementos de ésta consiste en la significación que es capaz. El significante sólo puede operar estando presente en el sujeto, porque el sentido sólo lo da este sujeto. Dice Lacan:

Lo que descubre esta estructura de la cadena significante es la posibilidad que tengo, justamente en la medida en que su lengua me es común con otros sujetos, es decir en que esa lengua existe, de utilizarla para significar muy otra cosa que lo que ella dice. Función más digna de subrayarse en la palabra que la disfrazar el pensamiento (casi siempre indefinible) del sujeto; a saber, la de identificar el lugar de ese sujeto en la búsqueda de lo verdadero (Lacan, 2005, p. 485).

En la cadena del significante el sentido insiste a través de un desplazamiento de un objeto significado. El significado pertenece al registro de lo real. Pero eso real se resiste a la simbolización. En otras palabras, es lo imposible para el sujeto. Implica ausencia. Ésta tiene que ser compensada 
para que la significación adquiera coherencia. Así, esta ausencia del significado es el motivo de la necesidad de una trasferencia del significado.

La simbolización tiene por consecuencia el que la identidad del sujeto tenga que ser adquirida a través de una mediación. Esta es la falta que hace imposible la adquisición de una identidad estable.

\section{La cuestión de la culpa y la interpelación}

¿Quién o qué es el Sujeto que interpela? ¿Por qué esa interpelación se vuelve efectiva? La formulación psicoanalítica freudiana y lacaniana muestra que la interpelación se posibilita a través de la constitución psíquica del sujeto en el ideal del yo o superyó. El llamado y el reconocimiento a ese llamado, la interpelación, son reconocidos porque forman parte de la estructura psíquica primaria. La autoridad, la ley, la norma, el deber ser, adquieren su forma en una relación dialéctica entre lo interior y exterior al sujeto. Esa autoridad, que es la que interpela, es, en primer momento, la voz del padre (ausente o presente de la madre o del padre), que al final es la mediación de la voz de la autoridad social y cultural. El ideal del yo dicta ciertos requisitos que deben ser seguidos por el sujeto para acercarse a la imagen ideal y construir algún tipo de identidad.

Sin embargo, de principio la incompletud del sujeto ante la interpelación del Sujeto es total. En el deber ser se juega la identidad y estabilidad del sujeto. Pero esa estabilidad es sumamente frágil porque el Sujeto exige al sujeto lo imposible que es la completud de su identidad. La factura de la fractura del sujeto que se exige a través de la interpelación se le carga a éste con la forma de la culpabilidad por mediación del ideal del yo.

La interpelación funciona porque el sujeto adquiere su forma psico-constitutiva en la interpelación del Sujeto.

¿Qué es la culpa? La culpa se constituye como un sentimiento que proviene de la sensación de trasgresión, real o ficticia, de una norma o una regla histórico-socialmente establecida. Se constituye como una reacción sicológica. Por ende subjetiva. Esto significa que dicho sentimiento tiene como motivo desencadenante una re-acción en la estructura psíquica del sujeto. Se origina 
por la sensación displacentera del quiebre de un orden estructural. Un orden que es conformado prioritariamente, de acuerdo con la teoría psicoanalítica freudiana-lacaniana, en la instancia del ideal del yo. Así, la estructura psíquica subjetiva se forja en la prohibición que se delinea en la dialéctica polémica ( $\pi 0 \lambda \varepsilon \mu \circ \varsigma)$ entre el yo y el superyó.

La culpa es un mecanismo psíquico que exige la restitución del orden quebrantado. Es importante insistir que al ser subjetiva, la realidad fáctica del quebrantamiento del orden pasa a un segundo término. La realidad esencial de la transgresión es psíquica, interna y personal. Por tal motivo el sentimiento de restitución del orden quebrantado puede tener o no que ver con un quebrantamiento factico de una norma, pero que su realidad no depende de esto último.

Asimismo, el sentimiento de culpa hace las veces de marco referencial de toma de decisiones en la que sus delineaciones se perfilan en el mantenimiento de un orden específico en contra de la transgresión del mismo.

Así, la interpelación, el llamado y mandato del Sujeto, tiene efecto porque el sujeto es receptivo a ésta. Es receptividad radica en la interiorización del sonido (de la voz) del mandato de la autoridad.

\section{Conclusiones. De vuelta al proceso}

Josef K. es culpable. ¿De qué es culpable? Es culpable de algo. No importa el delito o la transgresión. Esa culpabilidad lo hace responder a la interpelación que se le ha hecho; lo hace aceptar su castigo y encarar el proceso en su contra. La trasgresión ha sido grande e irrestituible. Sin embargo, siquiera K. sabe qué ha hecho. El sentimiento de culpa le proviene de las entrañas. K. muere terriblemente avergonzado. La vergüenza sólo puede soportarse en el sentimiento de culpa. La culpa de K. proviene de la interpelación que le ha hecho la ley. La ley tiene la forma jurídica, pero también tiene las formas familiares, escolares, laborales, nacionales, etc.

El sujeto desde siempre es sujeto. La identidad constitutiva del sujeto se conforma del mandato del Otro, del Sujeto. El Otro que tiene múltiples formas y múltiples caras; múltiples voces; habla desde y hacia la incompletud originaria del sujeto (el sujeto en falta). Pretenden completarlo. 
Hay la promesa de complitud no obstante su imposibilidad originaria. El sujeto está fracturado por la imposibilidad de ser sí mismo. Es más, el sí mismo es una ilusión creada por el Otro, por el Sujeto.

\section{Referencias}

Aguilar, M. (1984). Teoría de la ideología. México: UNAM.

Althusser, L. (1977). Posiciones. México: Grijalbo.

Freud, S. (2001). El yo y el ello (1923). Obras completas Vol. XIX. Buenos Aires: Amorrortu.

Kafka, F. (2001). El proceso. Madrid: Alianza Editorial.

Kafka, F. (2007). Consideraciones acerca del pecado, el dolor, la esperanza y el camino verdadero. México: Fontamara.

Lacan, J. (1985). El Seminario. Libro 1. Los escritos técnicos de Freud 1953-1954. Barcelona: Paídos. Lacan, J. (2005). Escritos Vol. 1. México: Siglo XIX.

Saussure, F. (1945). Curso de lingüística general. Buenos Aires: Editorial Losada.

Stavrakakis, Y. (2007). Lacan y lo político. Buenos Aires: Prometeo. 